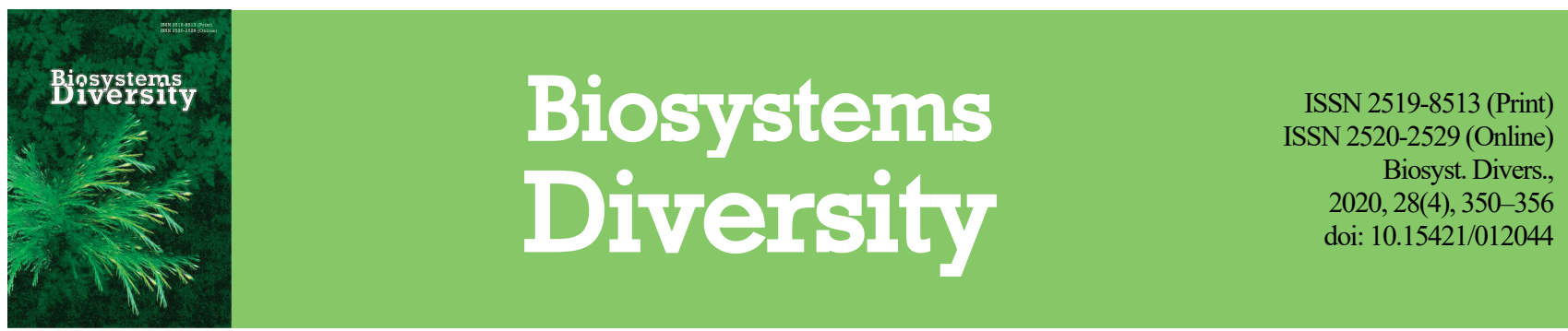

\title{
Soil and soil breathing remote monitoring: A short review
}

\author{
S. V. Nahirniak*, T. A. Dontsova*, A. V. Lapinsky*, M. V. Tereshkov*, R. C. Singh** \\ *National Technical University of Ukraine "Igor Sikorsky Kyiv Polytechnic Institute", Kyiv, Ukraine \\ **Guru Nanak Dev University, Amritsar, India
}

Article info

Received 18.10.2020

Received in revised form 12.11.2020

Accepted 14.11.2020

National Technical

University of Ukraine

"Igor Sikorsky Kyiv

Polytechnic Institute",

Peremogy av., 37,

Kyiv, 03056, Ukraine.

Tel.: +38-096-876-60-68.

E-mail:

nagirnyak_sv@ukr.net

Guru Nanak Dev University, Grand TrunkRoad,

Amritsar, 143005

Punjab, India.

Tel.: +91-991-412-99-39.

E-mail:rc.phy@gndu.ac.in

Nahirniak, S. V., Dontsova, T. A., Lapinsky, A. V., Tereshkov, M. V., \& Singh, R. C. (2020). Soil and soil breathing remote monitoring: A short review. Biosystems Diversity, 28(4), 350-356. doi:10.15421/012044

The efficiency of agricultural use of soils depends directly on their quality indicators, which include an extended set of characteristics: from data of the environmental situation to the component composition of the soil air. Therefore, for a more complete survey of agricultural land in order to determine their qualitative indicators and subsequent application, it is necessary to carry out comprehensive monitoring while simultaneously studying the characteristics of soils and their air composition. The article is devoted to the literature analysis on the remote monitoring of soils and soil air. Particular attention was paid to the relationship between soil type and soil air composition and it was found that the soil air composition (in the combination with $\mathrm{pH}$ and humidity parameters) can assess the type, quality and environmental condition of soils. Since when developing a remote monitoring system of soil air soil moisture and soil structure significantly affect the processes occurring in soils, and ultimately the quantitative composition of soil air, it is very important to know the dependence of the soil air composition on the type and quality of the soil itself, the influence of moisture, structure and other parameters on it. It was shown that the use of sensors is a promising direction for the development of the soils and soil air remote monitoring. It was indicated that soil and soil air remote monitoring in real time will provide reliable, timely information on the environmental status of soils and their quality. Commercial sensors that can be used to determine $\mathrm{CO}_{2}, \mathrm{O}_{2}, \mathrm{NO}_{\mathrm{x}}, \mathrm{CH}_{4}, \mathrm{CO}_{2} \mathrm{H}_{2}$ and $\mathrm{NH}_{3}$ were considered and the technique for sensor signal processing was chosen. A remote monitoring system with the use of existing commercial sensors was proposed, the movement of which can be realized with the help of quadcopter, which will allow parallel scanning of the soils and the land terrain. Such a system will make it possible to correctly assess the readiness of soils for planting, determine their intended use, correctly apply fertilizers, and even predict the yield of certain crops. Thereby, this approach will create a modern on-line system for full monitoring of soil, land and rapid response in the case of its change for the agro-industrial sector.

Keywords: remote monitoring; fertility indicators; soil air composition; sensors; e-nose.

\section{Introduction}

Indicators of soil fertility are directly related to the composition of soil air, the so-called "breath of the earth", which plays an important role in plant nutrition and is an indicator of biochemical and biological processes that occur in soil (Rolston, 2005; Smagin, 2005). The soil gas phase is close to atmospheric air but has a higher percentage of carbon dioxide, lower oxygen content, the presence of hydrogen sulfide and methane, and in the case of fertilizer overdose can have nitrogen oxides content as well.

Soil air is important for plant growth because it participates in the chemical and biochemical processes that flow into the soil; plays a role in the redox conditions in the soil; affects the solubility of soil chemical components. Soil air provides oxygen to plant roots and living organisms present in the soil and is an important factor in the carbon nutrition of plants, since most of the carbon dioxide consumed by crop growth is supplied by the soil.

Soil air consists of two groups of components including basic substances and impurities, the content of which does not exceed $100 \mathrm{ppm}$. The main components of the gas phase are oxygen, carbon dioxide, nitrogen, argon and water vapor. When the soil is excessively moistened by the anaerobiosis processes, the soil air composition can be replenished with reducing gases such as $\mathrm{H}_{2} \mathrm{~S}, \mathrm{H}_{2}, \mathrm{CO}, \mathrm{CH}_{4}$, in quantities at the level of the main components' content. The individual gases may be in the soil in the free state (in soil pores and voids), in the adsorbed state on the surface of the soil particles or in the dissolved state. The most important is the freesoil air, the content of which depends on the porosity and humidity of the soil. Carbon dioxide and oxygen are the most dynamic gases among all gases of soil air. It is known that $\mathrm{CO}_{2}$ content in the soil air is always hig- her than in the atmosphere and ranges from $0.2-0.5 \%$ to $1.0 \%$. The growth of plants depends on the $\mathrm{CO}_{2}$ concentration, and when it reaches its optimal concentration it is possible to accelerate the growth of the crop. Oxygen of soil air is essential for soil fertility and especially necessary for microbiological processes. It actively participates in chemical reactions of mineral and organic substances and is actively absorbed by roots of plants and microbes in the process of their breathing. Absence of free oxygen, similar to the accumulation of carbon dioxide, under the condition of excess moisture of soil suppresses the growth and development of plants. The optimum content of oxygen in the soil gas phase is about $20 \%$. The negative impact of soil air is shown at an oxygen content of less than $8-12 \%$ of the total, and if the oxygen content in the soil is less than $5 \%$ most of plants die. In normal aeration, the average composition of the soil gas phase is mainly determined by the ratio of the gas exchange intensity with the atmosphere and the processes of $\mathrm{O}_{2}$ absorption and $\mathrm{CO}_{2}$ emission. These intensity values can vary greatly depending on the thermodynamic conditions, the nature of the soil and the presence of living organisms in the soil.

The composition of the soil air varies significantly over time (during the day and depending on the season) and on the soil profile, depending on biological activity, hydrothermal conditions, gas adsorption and the intensity of gas exchange between the soil and atmosphere. As a result of biological processes, oxygen absorption and carbon dioxide emission constantly occur in the soil, which causes the soil to be depleted of oxygen and enriched with carbon dioxide. The release of $\mathrm{CO}_{2}$ in the process of diffusion depends on the carbon dioxide production by soil, physical and chemical properties of the soil, changes in hydrothermal conditions. Biological factors play a crucial role in this, which is why the release of $\mathrm{CO}_{2}$ 
can serve as a characteristic of the intensity of biological processes in the soil. As a result, soil breathing intensity is one of the indicators of soil biological activity.

In studying soil respiration, an important task is to obtain quantitative estimates of the contribution of different groups of living organisms to the exchange of $\mathrm{CO}_{2}$ and $\mathrm{O}_{2}$ with the atmosphere (Coleman, 1973; Kobak, 1988; Zavarzin \& Kudeyarov, 1993). The underground organs of plants, the processes of sorption and dissolution of gases have a great influence on the composition of soil air and its dynamics. Due to the porous structure, the soils have a large active surface that contributes to the sorption of gases. As the temperature increases, absorbed gases and vapors of substances are released from the soil surface, their content in the soil air increases. Increasing soil moisture accelerates the processes of gas desorption. The intensity of sorption processes in soil can outweigh the intensity of biological processes of carbon dioxide production and oxygen absorption. Thus, low values of the ratio of released $\mathrm{CO}_{2}$ to the amount of absorbed $\mathrm{O}_{2}$ (the so-called respiratory factor) may be related to physical processes rather than soil metabolic activity (Naumov, 2009). Underground plant organs, small soil animals, and microorganisms are biological sources of carbon dioxide and oxygen consumers. According to various researchers, the respiration of the underground plant organs is up to $30-40 \%$ of the total soil flow of carbon dioxide in agrocenoses.

Soil gas regime study is extremely important for agrochemical and microbiological studies. The soil gas regime is a set of all interrelated phenomena: the flow of gases into the soil and their movement along the soil profile; changes in the content and composition of gases in the soil air as a result of the absorption or release of individual gases in biological and biochemical processes, exchange between soil and atmosphere, solid and liquid phases. The soil gas regime consists of the following elements: air content; air composition; aeration and gas evolution. In soil studies periodic simultaneous selection (every 10-15 days or depending on the phase of plant development) of all these elements is required. At the same time, it is necessary to monitor the pressure and air temperature, temperature, and humidity of the soil.

Thus, all of the above demonstrates the existence of the relationship between the soil air composition and the physicochemical and microbiological parameters of soils, and therefore their fertility. Certainly, such factors as air humidity, soil moisture and soil structure significantly affect the processes occurring in soils, and ultimately the quantitative composition of soil air. Thereby, when developing remote monitoring of soil air, it is very important to know the dependence of the soil air composition on the type and quality of the soil itself, the influence of moisture, structure and other parameters on it, it seems equally important to choose sensors and detected gases correctly, and organize remote monitoring. All this together will make it possible to assess correctly the readiness of soils for planting, determine their intended use, correctly apply fertilizers, and even predict the yield of certain crops.

The aim of this work is to analyze the relationships presented in the modern literature between soil air and soil type, as well as the possibility of remote monitoring of soils and soil air using sensors.

\section{Methods for determination of soil breathing}

All soil breathing methods can be divided into methods of $\mathrm{CO}_{2}$ enrichment in an insulating device, ventilation methods and absorption methods (Bekku et al., 1997). In the first method, the initial and final concentrations of carbon dioxide in the air of an insulator located on the soil surface are determined. Determination of soil respiration by the second type of methods is carried out by drawing air through an insulator located on the soil surface. Absorption methods are implemented by placing a container with alkali that continuously absorbs $\mathrm{CO}_{2}$ over the surface of the soil.

The chamber method is the most common method for estimating the emission of gases and vapors (Mariko et al., 1994; Bekku et al., 1995; Pumpanen et al., 2009). To implement the method, remove the green parts of the plants and install a chamber for measuring soil respiration in the study area. After the chamber is installed, the original gas content is measured. After sampling, a gas analyzer determines the content of the test gas in the sample. Quantitative and more complete release of soil air occurs when it is displaced by liquid. In this method, a soil sample of a certain volume is usually selected with a 1 liter metal cylinder (height about $13 \mathrm{~cm}$, diameter $-10 \mathrm{~cm}$ ), the lower end of which is sharpened for easier immersion into the soil. To extract air from the selected soil sample, the cylinder is immersed in the tank of saturated $\mathrm{NaCl}$ solution on a special stand and connected to the gas receiver. After removing the plug under the solution, the latter enters the soil, displacing the air, which is drawn into the graded gas receiver.

Absorption methods for determining soil respiration are the simplest and do not require bulky equipment (Buyanovsky et al., 1986; Freijer \& Bouten, 1991). The principle of the method is to isolate the soil surface from the ambient air with a container under which a cup with alkali is placed to absorb $\mathrm{CO}_{2}$. After a certain period of time the tank is removed, and alkali titrated with acid.

All above mentioned methods require the use of bulky equipment and reagents. Thus, the search of new approaches for monitoring of soil gas phase is an important task which will allow us to create a method for determining the soil type and predict its quality in online mode. Promising from this point of view is a sensory method based on the use of sensory array - multi-sensor system "e-nose". This system will not require the use of reagents and will allow the determination of the content of the soil air components, in particular the content of $\mathrm{CO}_{2}, \mathrm{O}_{2}, \mathrm{NO}_{x}$, on-line.

Soil gas exchange and the relationship between soil quality and soil gas. In the soil gas is constantly exchanged with the environment, in which gases are intensively produced, transformed and consumed. The most important gas in the soil air is oxygen, which is necessary for the respiration of plant roots and is crucial for directing microbial metabolism, as well as for numerous biochemical and chemical reactions in the soil. It is transported from the atmosphere to the soil. The second important gas in the soil is carbon dioxide, which is an important product of oxygen respiration of plant roots, microorganisms, and meso- and macro-fauna, as well as oxygen-free microbial respiration and fermentation. In addition, it can be caused by certain chemical reactions in the soil. It is transferred from the soil to the atmospheric air. The most common component of the atmosphere and, in most cases, soil air is nitrogen. Its physiological role is associated with the nitrogen fixation by some groups of microbes. A further component is methane, which in drylands occurs in trace amounts, and in wetlands, as well as in special conditions such as landfills, can occupy a significant part of the soil air volume. Other microcomponents of soil air are nitrous oxide $\left(\mathrm{N}_{2} \mathrm{O}\right)$, nitric oxide $(\mathrm{NO})$ and dioxide $\left(\mathrm{NO}_{2}\right)$, ethylene, ammonia $\left(\mathrm{NH}_{3}\right)$ and hydrogen sulfide $\left(\mathrm{H}_{2} \mathrm{~S}\right)$ (Stępniewski et al., 2011).

Particular attention in the study of soils should be given to $\mathrm{CO}_{2}$, as an important marker of soil respiration, and as a result of soils quality and the processes occurring in them. Soil respiration is the sum of various processes in the soil that are associated with the global carbon cycle. It is generally believed that $\mathrm{CO}_{2}$ emissions are equal to the rate of soil respiration. However, in (Angert et al., 2015) it was shown that simultaneously measuring $\mathrm{CO}_{2}$ with $\mathrm{O}_{2}$ in the field and taking into account the soil profile, the biological respiration rate was 3.8 times higher than the surface $\mathrm{CO}_{2}$ measured in the chamber for the same soil. The measurements were carried out for different types of soils (temperate forest and two alpine forests) and included measurements of air samples from the soil profile and in the laboratory by incubation. It was also shown that the ratio between $\mathrm{CO}_{2}$ emissions and $\mathrm{O}_{2}$ influx (apparent respiration rate) was in the range from 0.14 to 1.23 and significantly deviated from 0.90 , which is characteristic of the elemental composition of plants and soil organic component. In soils with high $\mathrm{pH}$, these deviations are explained by $\mathrm{CO}_{2}$ dissolution in soil water and its conversion to bicarbonate ions, followed by the formation of carbonate minerals. In more acidic soils, this coefficient was unexpectedly low $(<0.70)$ and probably associated with the oxidation of reduced iron, which was previously formed under anaerobic conditions and in significantly wet soils.

It is well known that with aerobic respiration in moist soil (over a wide range of water content in the soil), the $\mathrm{CO}_{2}$ emission is a non-linear function of temperature, but becomes a linear function after soil dries. Lowering the groundwater level in organic soils (chernozems) increases the emission of soil carbon $\mathrm{CO}_{2}$ (but not in all soils) and reduces the amount of $\mathrm{CH}_{4}$ (the next most important marker of soil quality and microbiological processes in it) released into the atmosphere. At the same time, wetland soils emit a large amount of $\mathrm{CH}_{4}$ compared to other soil types. Soils satu- 
rated with oxygen due to intense microbial oxidation, on the contrary, absorb atmospheric $\mathrm{CH}_{4}$. The main criterion for the microbial oxidation rate, and hence $\mathrm{CH}_{4}$ absorption, is the gas diffusion coefficient, the temperature dependence in this case is small (Smith et al., 2018).

As already noted, soil moisture significantly affects the soil atmosphere, changing its composition as a result of evaporation and condensation. Oxygen levels in soil air are lower, and the level of carbon dioxide is higher compared to the aboveground gas atmosphere, while the concentrations of these gases are significantly dependent on soil moisture. Since the exchange of oxygen and carbon dioxide occurs on the soil surface, water penetrating the soil, causes a decrease in diffusion and at the same time lowers the oxygen content and increases the carbon dioxide content. Although this takes place in heavy soils (upper part, the first $30 \mathrm{~cm}$ ), in some light soils the composition of soil gas is close to atmospheric (Barnett \& Johnson, 2013).

Nitrous oxide is also a marker of soil quality and its emission increases markedly with increasing temperature, and this is due to an increase in the anaerobic process caused by increased $\mathrm{O}_{2}$ absorption. An increase in water-filled pore space also leads to increased anaerobic volume, and as result to an exponential increase in $\mathrm{N}_{2} \mathrm{O}$ emissions (Smith et al., 2018).

Studies on the soil air composition, the influence of physicochemical and microbiological parameters of soils on it, that is, their types, are few in the literature and go beyond the literature on soil science. It is explained by the interdisciplinarity of this issue, namely, to establish the relationships between soil air and soil type the interaction of soil biology and microbiology, chemistry and soil ecology, as well as soil physics, is necessary. Nevertheless, some studies in the modern literature are available, and they indicate that it is necessary to approach the study of soil respiration and establish the relationship between soil and soil air composition in a comprehensive manner, taking into account all parameters, such as soil humidity, temperature and $\mathrm{pH}$, soil air components $\left(\mathrm{CO}_{2}, \mathrm{O}_{2}, \mathrm{NO}_{\mathrm{x}}, \mathrm{CH}_{4}, \mathrm{CO}\right.$, $\mathrm{H}_{2}, \mathrm{H}_{2} \mathrm{~S}$ and $\mathrm{NH}_{3}$ ), humidity and temperature of the gas phase and others.

Usage of sensors for determining the soil air composition. The development of electronic nose (e-nose) for air monitoring has long been of interest to scientists because of the growing interest in ecology. This fact contributes to the development and improvement of environmental monitoring methods (Sviderskyi et al., 2018; Dontsova et al., 2019). The socalled e-nose mimics the human olfactory system and consists of several key elements: air sample delivery system; analysis system consisting of gas sensors array; signal processing system and special software (www.elprocus.com/electronic-nose-work).

The air sample delivery system provides sampling for an analysis system consisting of a group of sensors or sensor array that responds to the components of the gas environment. Contact of a sensors group or a sensor array with a gas medium of different composition causes changes in the electrical characteristics of these sensors. Thus, the interaction changes the electrical signal, which is converted to a digital value (Littarru, 2007; Dontsova et al., 2017; Nahirniak et al., 2018).

Today, the development of the e-nose environmental monitoring system, including the monitoring of such a new object as soil air, is of great interest because of the ability of this unit to recognize and distinguish different gases using only a small number of sensors (Röck et al., 2009; Wilson, 2012; Nagirnyak \& Dontsova, 2017). In air quality control, electronic noses can be used as an alternative to gas chromatography to evaluate air quality (Costello, 2003; Korotcenkov, 2007; Zhu et al., 2009). Finally, electronic noses can also be used as real-time process control tools, meaning that they can be remotely monitored for a long time. However, at present, the main limitation on the spread of e-nose technology as a means of environmental monitoring is its complexity and lack of specific regulation of its standardization, since its use entails a great deal of additional knowledge, such as data processing. Also, the use of e-nose is limited due to unstable and changing conditions. Despite this, e-nose systems are already being used to assess air pollution from various sources such as landfills, incineration plants, compressor plants and livestock farms (Wilson \& Baietto, 2009; Capelli et al., 2014; Zhang et al., 2017).

Currently, the following miniature gas sensors are the most promising for the e-nose development: metal oxide (semiconductor), electrochemical and optical (Fonollosa et al., 2015; Nagirnyak et al.; 2016; He et al., 2017), the advantages and disadvantages of which are given in Table 1.
Table 1

Advantages and disadvantages of sensors for use in the e-nose system

\begin{tabular}{lll}
\hline Sensor type & \multicolumn{1}{c}{ Advantages } & \multicolumn{1}{c}{ Disadvantages } \\
\hline $\begin{array}{l}\text { Metal } \\
\text { oxide }\end{array}$ & $\begin{array}{l}\text { High sensitivity, fast response } \\
\text { and recovery time at low concen- } \\
\text { trations }\end{array}$ & $\begin{array}{l}\text { High temperature, high power } \\
\text { consumption, moisture } \\
\text { sensitive, low accuracy }\end{array}$ \\
\hline $\begin{array}{l}\text { Electro- } \\
\text { chemical }\end{array}$ & $\begin{array}{l}\text { Operating ambient temperature, } \\
\text { low power consumption, very } \\
\text { sensitive to various volatile organic } \\
\text { compounds }\end{array}$ & $\begin{array}{l}\text { Large size, limited sensitivity } \\
\text { to gases at low concentration }\end{array}$ \\
\hline Optical & $\begin{array}{l}\text { Very high sensitivity, ability to } \\
\text { identify gases in mixtures }\end{array}$ & $\begin{array}{l}\text { Expensive in operation, low } \\
\text { level portability }\end{array}$ \\
\hline
\end{tabular}

Optical sensors measure the concentration of a particular gas in gas mixtures with high sensitivity and selectivity. However, their price is too high to be used in the e-nose system for environmental monitoring, in particular in soil air research. Electrochemical sensors have low power consumption and high sensitivity to a variety of volatile organic compounds, but the large size and low sensitivity to low concentrations of inorganic gases in the air make electrochemical sensors a poor candidate for portable air quality control devices.

Although semiconductor sensors consume more power, they are the most widely studied for e-nose generation, due to their low cost and various choices, such as the TGS Series produced by Figaro.

The authors of (He et al., 2017) developed the e-nose for daily monitoring of indoor air quality, the main components of which were the sensor array and the recognition algorithm. Sensor selection was implemented based on the measurement principle, cost, response to air pollutants and stability. In addition, temperature and humidity sensors were additionally installed. Signal processing was performed using the microprocessor on the MCU. Thus, the authors claim that the new type of e-nose was developed for indoor air monitoring, which was monitored by the built-in microprocessor. The authors also claim that measurements at the level of neural network processing have been achieved. The results of the statistical analysis show that the use of e-nose can achieve high results in continuous air monitoring. In the future, it will be necessary to focus on improving the prediction accuracy of the system under conditions where the target gas concentration is $<1 \mathrm{ppm}$.

Authors of (Wijaya et al., 2017) proposed a scheme for the mobile enose system usage for monitoring beef quality. In this case, the quality control system, that is, the e-nose module, is located in the place of control, and the component recognition system is run on the computer server. In addition, the authors argue that autonomous sensor processing can be integrated with a smart refrigerator to control meat quality and predict shelf life. Signals from all devices are transmitted over the wifi / GSM network to the primary server. Finally, the end user monitors beef quality from computer or smartphone. The system can also send beef quality notifications as messages to your phone or computer.

In this study, the sensor array consisted of 10 gas sensors (MQ135, MQ136, MQ2, MQ3, MQ4, MQ5, MQ6, MQ7, MQ8, MQ9), temperature and humidity detector (DHT22). Sensors were selected based on the Arduino platform. The Arduino Mega SDK was used as the main board for all components. In addition, the wifi-screen module was used to transmit data from sensor array to server.

Due to its fast and reliable approach electronic nose gas systems have attracted considerable attention for usage in agriculture, specifically for the plant insects and diseases diagnosis. Xu et al. (2017) showed the perspectives of e-nose usage for predicting the duration and prevalence of insect infestation in stored rough rice. In their work the authors used a sensor array of 10 metal oxide gas sensors sensitive to different volatile compounds. In their study Gębicki \& Szulczyński (2018) demonstrated the potential of an e-nose based on six Figaro's metal oxide semiconductor sensors for fast and efficient detection of fungi in peaches. Cui et al. (2019) in their work showed the possibility of using an e-nose system for fast diagnosis of aphid-stressed tomato plants at early infestation stages. The authors developed an electronic nose system equipped with four different sensors (for alcohol, volatile compounds, odorous gases and benzene detection), a signal circuit, data acquisition, fan and two gas pumps. The obtained results on the detection of volatile organic compounds emitted by tomato plants by the developed e-nose system agreed well with the results 
of investigations by gas chromatography mass spectometry. Thus, taking into account its obvious advantages, such as rapid and non-invasive detection, authors concluded the great potential of e-nose gas systems for insect control of plants at early stages. Thus, the use of an electronic nose to determine the soil air composition in order to establish the relationship with the quality and type of soil will be a promising online monitoring method. An important task is the choice of the correct sampling method and specialized selection of sensors for determining the composition of soil air and detectors for determining soil parameters.

Recently, the development of remote monitoring of soils and environmental parameters through the introduction of real-time wireless sensor systems has become increasingly popular (Roy \& Bandyopadhyay, 2013; Mahir et al., 2018). Soil moisture control systems are being successfully implemented to create efficient irrigation systems, which can significantly reduce freshwater consumption while improving the irrigation systems efficiency (Wang \& Qu, 2009; Kumar et al., 2014).

Implementation of remote soil monitoring in real time will provide reliable, timely information on soil status. It is known that the environmental, physical and chemical status of soils depends on many parameters such as soil parameters, climatic parameters, etc., which is directly reflected in the soil air composition. Therefore, a system that collects data on indicators such as $\mathrm{pH}$ and soil moisture, temperature and humidity of the soil air and its qualitative and quantitative composition in real time will allow the soil quality and ecological status to be evaluated and make it possible to respond in the case of emergency. A system consisting of the ATmega 328 microcontroller, DHT11 detector, soil hygrometer, light intensity sensor, soil $\mathrm{pH}$ detector and MQ-135 sensor was developed in the work (Balakrishna et al., 2016). This system was used to control irrigation parameters. The obtained results showed that such system can increase the efficiency of scientific and agricultural practice.

The most effective way to organize remote monitoring of soil and soil air to determine their quality will be the usage of a system with a separate stand-alone measuring unit that will collect samples, measure composition and parameters, and then send raw data over a wireless communication channel or in another way to the main station or server that will perform the data analysis, necessary calculations and display the data conveniently.

The measuring unit should be equipped with the necessary set of sensors, battery, wireless transmitter and sampling device, such as a tube which can be immersed several centimeters into the ground, or a dome that reduces the influence of external conditions on measurements. Optionally, it is possible to equip measuring units with solar panels, which in the case of permanent placement of the unit will significantly increase the autonomy in the sunny season.

Hardware solutions that implement existing IoT protocols such as ZWave, ZigBee, BLE can be used for data transfer (Fitriawan et al., 2017). Usually such solutions have a maximum effective distance of up to 50 or less than $100 \mathrm{~m}$, since the data transmission capacity is limited at the legislative level in almost all countries. Using 443,868 , and $915 \mathrm{MHz} \mathrm{LoRa}^{\circledR}$ technology implemented by Semtech Corp. modules allows one to place transmitters (as a part of measuring units) at a distance of $500 \mathrm{~m}$ to several kilometers (www.semtech.com/products/wireless-rf). Nordic Semiconductor also offers a wide range of wireless hardware solutions (www.nordicsemi.com/Products). The advantage of such system is low power consumption of autonomous sensor blocks, the absence of the need for cellular coverage and the ability to integrate the measuring blocks into a mesh network.

For cellular-enabled areas, the solution may be to equip each sensor unit with a cellular network module with GSM, UMTS / CDMA or LTE standards. This will allow one to send data from the sensor sets via the Internet to dedicated servers that will receive the raw data, perform the necessary analysis and archive data. In addition, in most countries, cellular operators have special rates for IoT to optimize data costs.

An alternative solution is to place a sensor block on a land or air mobile platform, such as a quadcopter. The complex of the mobile platform and sensor unit will allow monitoring in almost any location, eliminating the need for physical access to the units for regular maintenance and covering large areas without additional sensor costs. If necessary, certain measurements can be made while moving, which will allow two- or three-dimensional maps of specific indicators to be created to estimate the overall state of the atmosphere of a particular area. In addition, there is no need to maintain a permanent connection of the measuring unit to the base station/ server, data collection may occur after the mobile platform is returned to the user. The mobile platform can operate completely autonomously, bypassing the necessary points for measurements by a customized algorithm and coordinates.

\section{Sensors for determining the content of soil air components}

Carbon dioxide. Under normal conditions carbon dioxide is a gas without colour and odour but has a slightly acidic taste. It is the product of the life of all living organisms on earth. To control its concentration electrochemical, optical and semiconductor sensors and their sets are used.

Electrochemical sensors of carbon dioxide have gained the most popularity due to the better combination of price and accuracy. Carbon dioxide sensors from the Swiss company Membrapor occupy a leading position in the market due to the good quality and large number of variants of $\mathrm{CO}_{2}$ sensors in the manufacturer's nomenclature (www.membrapor.ch). Carbon dioxide sensors from the Japanese company Nemoto are not inferior in quality and popularity (www.nemoto.eu/products.html). Optical $\mathrm{CO}_{2}$ sensors have better performance in terms of durability, reliability, selectivity, but have not gained wide popularity in the market on account of the high cost. Semiconductor sensors of carbon dioxide have the lowest cost. The disadvantages of $\mathrm{CO}_{2}$ sensors of this type include the instability of readings and cross-sensitivity to other gases (www.gassensor.ru/ $\mathrm{ru} /$ gas/uglekislyi-gas-co2).

Oxygen. Oxygen $\left(\mathrm{O}_{2}\right)$ is not a toxic substance, has no taste, colour or odour. It can be detected by gas analytic equipment such as sensor blocks (transducers) and oxygen sensors. Electrochemical, optical and polymer sensors are the most popular for oxygen detection.

Electrochemical oxygen sensors have become widespread. Electrochemical oxygen sensors are a cell with an electrolyte and electrodes closed with a filter. These oxygen sensors are used in stationary and portable gas analyzers. Optical oxygen sensors have greater reliability and longer life. Optical oxygen sensors are used in cases where long-term operation of the unit without maintenance is required. The main sensor manufacturer is company SST, UK (www.sstsensing.com). Polymeric oxygen sensors are new in gas analytics, but their principle of construction is similar to electrochemical sensors. Compared to electrochemical oxygen sensors, the polymer sensors are smaller in size and can be completed in small enclosures (www.gassensor.ru/ru/gas/kislorod-o2).

Nitrogen oxides. Nitrogen dioxide $\left(\mathrm{NO}_{2}\right)$ is a red-brown gas with characteristic acrid odour. In the atmosphere, nitrogen dioxide is a serious hazard because it is capable of causing toxic body damage and acid rain. In general, only electrochemical $\mathrm{NO}_{2}$ sensors are common, which is related to the characteristics of this gas.

Electrochemical $\mathrm{NO}_{2}$ sensors have high selectivity, low cost and different nomenclature options. The most popular on the market are sensors for the detection of nitrogen dioxide from Membrapor company (www.membrapor.ch). This is due to the wide choice of measurement ranges, specifications and sensor sizes. $\mathrm{NO}_{2}$ sensors of AlphaSense company, which show better sensitivity across different measurement ranges, are not inferior (www.alphasense.com/index.php/products/nitrogen-dioxide). Quality $\mathrm{NO}_{2}$ sensors are also available from Sixth Sense and Nemoto companies (www.nemoto.eu/products.html; www.syxthsense.com/category?cat=Sen sors). Polymeric sensors for the nitrogen dioxide detection are new in gas analysis and are currently distinguished by their low cost and long service life. However, these $\mathrm{NO}_{2}$ sensors have not yet been able to prove themselves with excellent specifications (www.gassensor.ru/ru/gas/dioksidazota-no2).

Nitrogen oxide (NO) is a colourless gas that is harmful to the human body. To date, only electrochemical sensors are used for NO detection (www.gassensor.ru/ru/gas/oksid-azota-no).

Methane. Under normal conditions, methane $\left(\mathrm{CH}_{4}\right)$ is a colourless odourless gas. There is evidence that methane is a toxic substance acting on the central nervous system. Accumulating indoors, methane is explosive.

Due to low prices, high quality and low energy consumption, methane sensors of the Nemoto company are the most famous (www.nemoto. co.jp/nse/sensor-search/gas/methane). Fis Inc. company is one of the 
world's leading manufacturers of semiconductor gas sensors and produces several $\mathrm{CH}_{4}$ gas sensor types with excellent performance and low power consumption. Sensors of Fis Inc. are characterized by high sensitivity to methane, low sensitivity to noise gases, quick response speed and strong poisoning resistance (www.fisinc.co.jp/en/products). Dynament company produced infrared low power methane sensors with the detection lever in the range $0-100 \% \mathrm{vol}$ (www.dynament.com/gas-types/methane). Besides single methane detection the company provides dual gas methane/carbon dioxide sensors.

Carbon monoxide. Carbon monoxide (CO) is a gas without colour, odour and taste. It is a product of incomplete combustion of carbon-containing materials and in small amounts it is produced in the metabolism process of animals. The detection of $\mathrm{CO}$ content in the atmosphere is possible by opto-chemical, biomimetic, electrochemical, and semiconducting detectors.

Optical gas sensors that can detect carbon monoxide concentrations in the range from 0 to $5000 \mathrm{ppm}$, as well from 0 to $100 \mathrm{vol} . \%$, are available from the SmartGAS company (www.smartgas.eu/gase/co). Biomimetic detectors are the new sensor type which consist of special gel which similar to hemoglobin, in the $\mathrm{CO}$ presence it turns a different colour. Biomimetic sensors belong to the most reliable type but have not become widespread due to high cost (www.vivint.com/resources/article/how-do-carbon-monoxide-detectors-work). Electrochemical sensors are the most commonly used for $\mathrm{CO}$ detection due to their advantages such as low power consumption and long lifespan. Nowadays the main producers of electrochemical $\mathrm{CO}$ sensors with the different measurement ranges are AlphaSense (www.alphasense.com), City Technology (www.citytech.com) and Membrapor (www.membrapor.ch). Metal oxide semiconducting sensors are less commonly used for $\mathrm{CO}$ detection because in comparison with electrochemical they require substantial power.

Hydrogen. Hydrogen $\left(\mathrm{H}_{2}\right)$ is a colourless and odourless gas without taste. Hydrogen is not toxic, but extremely flammable and forms an explosive mixture with oxygen.

Electrochemical, semiconductor, thermocatalytic and polymer gas sensors are used for hydrogen detection (www.gassensor.ru/en/gas/hydrogen-h2). Electrochemical and semiconductor sensors are the most commonly used as they are able to detect $\mathrm{H}_{2}$ at low concentration levels. Electrochemical hydrogen sensors are most widely used due to good technical characteristics, and low cost. Membrapor (www.membrapor.ch) is the market leader for $\mathrm{H}_{2}$ sensors production and provides a great choice of $\mathrm{H}_{2}$ detectors of different size and sensitivity. AlphaSense $\mathrm{H}_{2}$ sensors are not inferior to the Membrapor sensors in terms of product quality, but their main advantage is high sensitivity at various ranges. Semiconductor hydrogen sensors favourably differ in low cost, but at the same time, they have not the best technical characteristics (cross sensitivity and instability of readings) (Nahirniak et al., 2019). Thermocatalytic hydrogen sensors are characterized by a wide range of operating temperatures, low cost, but like semiconductor sensors are characterized by unstable parameters. Hydrogen polymer sensors are a novelty in the gas analytics market and at the moment they demonstrate not the best indicators of selectivity, but their long service life and low price are an undoubted advantage.

Hydrogen sulfide. Hydrogen sulfide $\left(\mathrm{H}_{2} \mathrm{~S}\right)$ is a poisonous, corrosive, highly flammable, explosive and extremely toxic gas. it is produced by microbial breakdown and commonly present during oil and natural gas production, and in sewers.

$\mathrm{H}_{2} \mathrm{~S}$ detectors shall have fast response time and sturdy construction to operate in the harsh conditions where hydrogen sulfide may occur. To date, only electrochemical and semiconductor sensors are used to detect hydrogen sulfide (www.gassensor.ru/en/gas/hydrogen_sulfide-h2s). Due to the small size, low cost, fast response time and ability to operate in wide temperature and humidity ranges electrochemical sensors are the most common for hydrogen sulfide detection (www.gdscorp.com/h2s-sensor).

Ammonia. Ammonia is a colourless gas with a pungent characteristic odour, has a toxic effect on the human body. Ammonia is one of the main products of the chemical industry in the production of fertilizers, explosives, medicine, polymers, nitric acid, etc.

Electrochemical, semiconductor and optical sensors are used to monitor $\mathrm{NH}_{3}$ concentrations. Electrochemical sensors have gained the most popularity due to the best combination of price and reliability of readings. Ammonia sensors from the Swiss company Membrapor occupy a leading position due to their good quality and wide variety (www.membrapor.ch). Ammonia sensors from the Japanese company Nemoto are not inferior in quality and popularity (www.nemoto.eu/products.html). The latest innovations in the ammonia sensor market became sensors from SolidSense and SGX Sensortech companies, which proved to be the best in testing. Semiconductor ammonia sensors have the lowest cost. The disadvantages of this type of ammonia sensors include instability of readings and crosssensitivity to other gases. Optical ammonia sensors have the best characteristics in terms of durability, reliability, selectivity. But, optical sensors $\mathrm{NH}_{3}$ have not gained wide popularity in the market due to the high cost.

\section{Development of remote monitoring using existing commercial sensors}

Establishing an effective remote monitoring system using existing commercial sensors is possible today. Sensors most suitable for this purpose and their characteristics are shown in Table 2.

The primary processing of sensor signals can be successfully implemented with a microcontroller which has sufficient number of digital and analogue channels with the ability to communicate with data storage and wireless communication devices. For this purpose, AVR microcontrollers from Microchip Technology, such as Atmega2560, or ARM microcontrollers from STMicroelectronics, such as STM32F103, may be used.

\section{Table 2}

Types and characteristics of commercial sensors for the creation of the remote monitoring system

\begin{tabular}{|c|c|c|}
\hline Sensor & Characteristic & Source \\
\hline $\begin{array}{l}\text { Temperature/humidity } \\
\text { /ATM. Pressure BME280 }\end{array}$ & $\begin{array}{l}\text { combines three indicators measuring, has high accuracy, digital interface, } \\
\text { small size and very low power consumption }\end{array}$ & $\begin{array}{l}\text { (www.bosch-sensortec.com/products/environmental- } \\
\text { sensors/humidity-sensors-bme280) }\end{array}$ \\
\hline $\begin{array}{l}\mathrm{CO}_{2} \\
\mathrm{MHZ}-14 \mathrm{~A}\end{array}$ & $\begin{array}{l}\text { optical sensor with a fairly wide measurement range, sufficient precision, } \\
\text { high selectivity, digital and analog interfaces }\end{array}$ & (www.winsen-sensor.com/sensors/co2-sensor/mh-z14a.html) \\
\hline $\begin{array}{l}\mathrm{O}_{2} \\
\text { LuminOx Optical }\end{array}$ & optical sensor with high accuracy, fairly fast response and digital interface & $\begin{array}{l}\text { (www.sstsensing.com/product/luminox-optical-oxygen- } \\
\text { sensors-2) }\end{array}$ \\
\hline $\begin{array}{l}\mathrm{NO}_{2} \\
\text { SS Gas Sensor }\end{array}$ & solid electrolyte, has high sensitivity, low response time and analog interface & $\begin{array}{l}\text { (euro-gasman.com/product/nitrogendioxide-no2-ss-gas- } \\
\text { sensor-micro-version-2) }\end{array}$ \\
\hline $\begin{array}{l}\mathrm{CO} \\
\text { SS Gas Sensor }\end{array}$ & $\begin{array}{l}\text { solid electrolyte, has high sensitivity, fast response time and high selectivity, analog } \\
\text { interface }\end{array}$ & $\begin{array}{l}\text { (euro-gasman.com/product/carbonmonoxide-co-ss-gas- } \\
\text { sensor-micro-version-2) }\end{array}$ \\
\hline $\begin{array}{l}\mathrm{H}_{2} \\
\text { SS Gas Sensor }\end{array}$ & $\begin{array}{l}\text { has greater sensitivity compared to liquid electrolytic sensors (up to } 1 \mathrm{ppm} \text { ), has } \mathrm{H}_{2} \mathrm{~S} \\
\text { filter, analog interface }\end{array}$ & $\begin{array}{l}\text { (euro-gasman.com/product/hydrogen-h2-ss-gas-sensor- } \\
\text { micro-version) }\end{array}$ \\
\hline $\begin{array}{l}\mathrm{H}_{2} \mathrm{~S} \\
\text { Solidsense } 4-\mathrm{H}_{2} \mathrm{~S}-\mathrm{HR}-\end{array}$ & $\begin{array}{l}\text { high sensitivity electrolytic sensor }(0.1 \mathrm{ppm}) \text {, has low response time, high precision, } \\
\text { analog interface }\end{array}$ & $\begin{array}{l}\text { (euro-gasman.com/product/hydrogensulphide-h2s-ss-gas- } \\
\text { sensor-7) }\end{array}$ \\
\hline $\begin{array}{l}\mathrm{NH}_{3} \\
\text { Solidsense 7-NH} 3-1000\end{array}$ & $\begin{array}{l}\text { electrolytic sensor with high sensitivity }(<3 \mathrm{ppm}) \text { and selectivity in comparison with } \\
\text { analogues, analog interface }\end{array}$ & (euro-gasman.com/product/ammonia-nh3-ss-gas-sensor-4) \\
\hline $\begin{array}{l}\mathrm{CH}_{4} \text { Komyo Kitagawa } \\
\text { SC-403 }\end{array}$ & semiconductor high-sensitivity sensor with high selectivity and analog interface & $\begin{array}{l}\text { (euro-gasman.com/product/methane-ch4-semiconductor-gas- } \\
\text { sensor) }\end{array}$ \\
\hline
\end{tabular}

These microcontrollers are quite cheap, have sufficient power and hardware capabilities, are well established in the market and can be used to develop hardware solutions based on them and in the form of ready-touse boards. The use of common microcontroller models also reduces the 
time and cost of the software development. Installation and relocation of the monitoring system is possible through the use of quadcopter, which will allow one also to scan the terrain of soil and land.

\section{Conclusions}

It is shown that remote monitoring of soil and soil air using sensors in real time is a promising direction for assessing the environmental conditions of soils, their suitability for agricultural purposes and rapid response in the case of any problem. Therefore, such soil and soil air remote monitoring will ensure reliable and timely information on soil condition.

It is demonstrated that there is a relationship between soil quality and soil air composition, which, in addition to traditional soil assessment ( $\mathrm{pH}$, humidity, carbon dioxide), can also be used to assess soil quality and environmental conditions. Based on our review of current researches, it can be concluded that the electronic nose will be the most promising monitoring method for determination the composition of the soil air in order to establish the relationship with the quality and type of soil. An important task in this case is the correct selection of sensors to determine the composition of the soil air and detectors to determine soil parameters, as well as correct soil air sampling organization.

Commercial sensors for the determination of $\mathrm{CO}_{2}, \mathrm{O}_{2}, \mathrm{NO}_{\mathrm{x}}, \mathrm{CH}_{4}$, $\mathrm{CO}, \mathrm{H}_{2}, \mathrm{NH}_{3}$ are considered and the most suitable for creating an effective real time remote monitoring system are selected. The technique for sensor signal processing was chosen. The quadcopter usage for moving sensor units for soil air monitoring and detectors for soil parameters measurement was justified. In addition, such a quadcopter system will allow the scanning of soil and ground terrain. This approach will create a modern on-line system for full monitoring of soil, land and rapid response in the case of its change for the agro-industrial sector.

\section{References}

Angert, A., Yakir, D., Rodeghiero, M., Preisler, Y., Davidson, E. A., \& Weiner, T. (2015). Using $\mathrm{O}_{2}$ to study the relationships between soil $\mathrm{CO}_{2}$ efflux and soil respiration. Biogeosciences, 12, 2089-2099.

Balakrishna, K., Nethravathi, S. N., \& Harshitha, K. (2016). Real-time soil monitoring system for the application of agriculture. International Journal of Engineering Science and Computing, 6(5), 5326-5331.

Barnett, K., \& Johnson, S. N. (2013). Chapter one-living in the soil matrix: Abiotic factors affecting root herbivores. In: Johnson, S. N., Hiltpold, I., \& Turlings, T. C. J. (Ed.). Advances in Insect Physiology. Academic Press, Oxford. Vol. 45. Pp. $1-52$.

Bekku, Y., Koizumi, H., Nakadai, T., \& Iwaki, H. (1997). Examination of four methods for measuring soil respiration. Applied Soil Ecology, 5(3), 247-254.

Buyanovsky, G. A., Wagner, G. H., \& Gantzer, C. J. (1986). Soil respiration in a winter wheat ecosystem. Soil Science Society of America Joumal, 50(2), 338-344.

Capelli, L., Siron, S., \& Del Rosso, R. (2014). Electronic noses for environmental monitoring applications. Sensors, 14, 19979-20007.

Coleman, D. C. (1973). Soil carbon balance in a successional grassland. Oikos, Lund, 24(2), 195-199.

De Lacy Costello, B. P. J., Ewen, R. J., Ratcliffe, N. M., \& Sivanand, P. S. (2003). Thick film organic vapour sensors based on binary mixtures of metal oxides. Sensors and Actuators B: Chemical, 92, 159-166.

Cui, S., Inocente, E. A. A., Acosta, N., Keener, H. M., Zhu, H., \& Ling, P. P. (2019) Development of fast e-nose system for early-stage diagnosis of aphid-stressed tomato plants. Sensors, 19, 3480.

Dontsova, T. A., Nagirnyak, S. V., Zhorov, V. V., \& Yasiievych, Y. V. (2017). $\mathrm{SnO}_{2}$ nanostructures: Effect of processing parameters on their structural and functional properties. NanoScale Research Letters, 12, 332

Dontsova, T. A., Nahimiak, S. V., \& Astrelin, I. M. (2019). Metaloxide nanomaterials and nanocomposites of ecological purpose. Journal of Nanomaterials, 2019,5942194

Fitriawan, H., Susanto, M., Arifin, A. S., Mausa, D., \& Trisanto, A. (2017). ZigBee based wireless sensor networks and performance analysis in various environments. 15th International Conference on Quality in Research (QiR): International Symposium on Electrical and Computer Engineering. Nusa Dua, Indonesia. Pp. 272-275.

Fonollosa, J., Rodriguez-Lujan, I., \& Huerta, R. (2015). Chemical gas sensor array dataset. Data in Brief, 3, 85-59.

Freijer, J. I., \& Bouten, W. (1991). A comparison of field methods for measuring soil carbon dioxide evolution: Experiments and simulation. Plant and Soil, 135, 133-142.
Gębicki, J., \& Szulczyński, B. (2018). Discrimination of selected fungi species based on their odour profile using prototypes of electronic nose instruments. Measurement, 116, 307-313

He, J., Xu, L., Wang, P., \& Wang, Q. (2017). A high precise e-nose for daily indoor air quality monitoring in living environment. Integration, 58, 286-294.

Kobak, K. I. (1988). Bioticheskie komponenty uglerodnogo cikla [Biotic components of the carbon cycle]. Gidrometeoizdat, Leningrad (in Russian).

Korotcenkov, G. (2007). Metal oxides for solid-state gas sensors: What determines our choice? Materials Science and Engineering: B, 139(1), 1-23.

Kumar, J. P., Umar, S., Harsha, C. S., \& Nagasai, B. (2014). Implementing intelligent monitoring techniques in agriculture using wireless sensor networks. International Joumal of Computer Science and Information Technologies, 5(4), 5797 5800 .

Littarru, P. (2007). Environmental odours assessment from waste treatment plants: Dynamic olfactometry in combination with sensorial analysers "electronic noses". Waste Management, 27(2), 302-309.

Mahir, A., Banavalikar, T., Budukh, M., Dhodapkar, S., \& Dhumane, A. V. (2018). Soil monitoring system using Zigbee for smart agriculture. International Journal of Science Technology and Engineering, 4(7), 32-38.

Mariko, S., Bekku, Y., \& Koizumi, H. (1994). Efflux of carbon dioxide from snowcovered forest floors. Ecological Research, 9(3), 343-350.

Nagimyak, S. V., Lutz, V. A., Dontsova, T. A., \& Astrelin, I. M. (2016). The effect of the synthesis conditions on morphology of tin (IV) oxide obtained by vapor transport method. In: Fesenko, O., \& Yatsenko, L. (Ed.). Nanophysics, nanophotonics, surface studies, and applications. Springer Proceedings in Physics, Springer, 183, 331-342.

Nagimyak, S. V., \& Dontsova, T. A. (2017). Gas sensor device creation. 7th International Conference on Nanomaterials: Applications and Properties, IEEE, Odessa. Pp. 1-4.

Nahimiak, S., Dontsova, T., \& Astrelin, I. (2018). Directional synthesis of $\mathrm{SnO}_{2}$ based nanostructures for use in gas sensors. In: Fesenko, O., \& Yatsenko, L. (Ed.). Nanochemistry, boitechnology, nanomaterials, and their applications. Springer Proceedings in Physics, Springer. Vol. 214. Pp. 233-245.

Nahimiak, S. V., Dontsova, T. A., \& Chen, Q. (2019). Sensing properties of $\mathrm{SnO}_{2}$ MWCNTs nanocomposites towards $\mathrm{H}_{2}$. Molecular Crystals and Liquid Crystals, 674(1), 48-58.

Naumov, A. V. (2009). Dyhanie pochvy: Sostavlyayushchie, ekologicheskie funkcii, geograficheskie zakonomernosti [Soil respiration: Components, environmental functions, geographical patterns]. SB RAS, Novosibirsk (in Russian).

Pumpanen, J., Longdoz, B., \& Werner, L. K. (2009). Field measurements of soil respiration: Principles and constraints, potentials and limitations of different methods. In: Kutsch, W. L., Bahn, M., \& Heinemeyer, A. (Ed.). Soil carbon dynamics: An integrated methodology. Cambridge University Press, Cambridge. Pp. 16-33.

Röck, F., Barsan, N., \& Weimar, U. (2008). Electronic nose: Current status and future trends. Chemical Reviews, 108(2), 705-725.

Rolston, D. E. (2004). In: Hiller, D. (Ed.). Aeration. Encyclopedia of soils in the environment. Academic Press, Cambridge. Pp. 17-21.

Roy, S., \& Bandyopadhyay, S. (2012). A test-bed on real-time monitoring of agricultural parameters using wireless sensor networks for precision agriculture. In: International Conference on Intelligent Infrastructure at 47th Annual National Convention of the Computer Society of India, Kolkata. P. 7.

Smagin, A. V. (2005). Gazovaya faza pochv [Gas phase of soils]. Moscow State University, Moscow (in Russian).

Smith, K. A., Ball, T., Conen, F., Dobbie, K. E., Massheder, J., \& Rey, A. (2018). Exchange of greenhouse gases between soil and atmosphere: Interactions of soil physical factors and biological processes. European Journal of Soil Science, 69(1), 10-20.

Stępniewski, W., Stepniewska, Z., Rożej, A., Hatfield, J. L., \& Sauer, T. J. (2011). Gas exchange in soils. In: Hatfield, J. L., \& Sauer, T. J. (Ed.). Soil management: Building a stable base for agriculture. ASA, CSSA, and SSSA Books, Madison. Pp. 117-144.

Sviderskyi, A., Yashchenko, T., Nahirniak, S., Dontsova, T., \& Kalinowski, S. (2018). Properties of $\mathrm{TiO}_{2}$ and $\mathrm{SnO}_{2}$ in a state of different dispersion and morphology. 8th International Conference on Nanomaterials: Applications and Properties. IEEE, Zatoka. Pp. 246-249.

Wang, L., \& Qu, J. J. (2009). Satellite remote sensing applications for surface soil moisture monitoring: A review. Frontiers of Earth Science in China, 3(2), 237-247.

Wijaya, D. R., Sarno, R., Zulaika, E., \& Sabila, S. I. (2017). Development of mobile electronic nose for beef quality monitoring. Procedia Computer Science, 124, $728-735$.

Wilson, A. D. (2012). Review of electronic-nose technologies and algorithms to detect hazardous chemicals in the environment. Procedia Technology, 1, 453-463.

Wilson, A. D., \& Baietto, M. (2009). Applications and advances in electronic-nose technologies. Sensors, 9(7), 5099-5148

Xu, S., Zhou, Z., Li, K., Jamir, S. M., \& Luo, X. (2017). Recognition of the duration and prediction of insect prevalence of stored rough rice infested by the red flour beetle (Tribolium castaneum Herbst) using an electronic nose. Sensors, 17(4), 688. 
Zavarzin, G. A., \& Kudeyarov, V. N. (1993). Dyhanie pochvy [Respiration of the soil]. Pushchino (in Russian).

Zhang, Y., Zhao, J., Du, T., Zhu, Z., Zhang, J., \& Liu, Q. (2017). A gas sensor array for the simultaneous detection of multiple VOCs. Scientific Reports, 7, 1960.
Zhu, C. L., Chen, Y. J., Wang, R. X., Wang, L. J., Cao, M. S., \& Shi, X. L. (2009) Synthesis and enhanced ethanol sensing properties of $\alpha-\mathrm{Fe}_{2} \mathrm{O}_{3} / \mathrm{ZnO}$ heteronanostructures. Sensors and Actuators B: Chemical, 140(1), 185-189. 